\title{
O gênero entre a lei e a norma
}

PEDRO AMBRA ${ }^{I}$

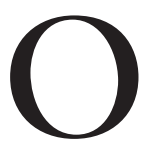

GÊNERO parece ter se tornado uma categoria incontornável não apenas na discussão acadêmica em ciências humanas, mas igualmente no interior do corpo social. A edição especial de janeiro de 2017 da National Geographic é enfática em seu título, “A revolução do gênero" (Henig, 2017), ao sintetizar a força que a noção adquiriu em escala quase global. No contexto brasileiro, raras são as semanas em que não há especiais sobre "transexuais" e "identidade de gênero" em veículos de mídia de grande alcance. Mas nem toda manifestação causada pela presença dessa questão na sociedade sublinha o alcance de seu impacto da mesma forma. Muitas delas, por exemplo, rechaçam o gênero por considerá-lo uma construção falsa, que negaria a verdade da diferença sexual.

Junto a grupos conservadores e até mesmo no Congresso Nacional, uma das grandes bandeiras da chamada "bancada da bíblia" é - ao lado da proibição de adoção por casais homoparentais e da criminalização da "heterofobia" - justamente o combate à “ideologia de gênero", que seria definida da seguinte forma: "A Ideologia de Gênero, ou melhor dizendo, a Ideologia da Ausência de Sexo, é uma crença segundo a qual os dois sexos - masculino e feminino - são considerados construções culturais e sociais [...]" (Sofos, 2017, grifado no original). Na mesma toada, Schnake (2017) afirma que a "ideologia de gênero" seria uma tentativa de afirmar "que não existe uma identidade biológica em relação à sexualidade. Quer dizer que o sujeito, quando nasce, não é homem nem mulher, não possui um sexo masculino ou feminino definido, pois, segundo os ideólogos do gênero, isto é uma construção social". Da mesma forma, para Bacarji (2017):

Um dia, ouvi, na homilia de um padre da Canção Nova, uma fala muito interessante: um homem que troca de sexo, colocando útero e seios, sempre será um homem com útero e seios, nunca uma mulher. Mas a ideologia de gênero deseja incutir essa falta de realidade em nossa cabeça, dizendo que podemos ser o que quisermos e que é natural nascer homem e passar a ser mulher por causa da opção sexual. Sendo que as crianças e os adolescentes poderão, ingenuamente, crer nisso.

Mas, para nosso espanto, a essência de tal posição argumentativa não é muito diferente de certos discursos lacanianos, para quem

Na constituição de um "futuro psicótico" ocorre exatamente a falta da inscrição normativa do complexo de castração que impede o reconhecimento e aceitação da diferença sexual como acontece nas neuroses. Assim, é urgente o combate à ideologia de gênero que, com a noção de igualdade de gênero e o incentivo às relações homoparentais, coloca em risco as diferen- 
ças sexuais que possuem função estruturante no desenvolvimento psíquico da criança. (Soares, 2017)

Assim, ainda que opostos em seus embasamentos teóricos e éticos, no que tange a sexuação os argumentos nos campos religioso e psicanalítico, seus pontos de partida e efeitos são espantosamente similares: haveria uma diferença sexual (seja biológica, seja simbólica) que é em si intocável pela cultura; e, portanto, falar sobre construções e desconstruções em relação à diferença sexual seria, no mínimo, equivocado e, no limite, perigoso. Tal argumentação se respalda na ideia - presente em Lacan e hipertrofiada por comentadores - segundo a qual a diferença sexual não é o gênero, pois remetida ao simbólico (ou, para alguns, ao real $l^{1}$ e, portanto, não cultural. Mas seria tal oposição entre cultura e estrutura simbólica e, portanto, entre identidades de gênero e o sujeito da psicanálise de fato embasada nas matrizes do estruturalismo evocadas por Lacan na proposição de sua teoria? Tomemos o famigerado complexo de Édipo como ponto de partida de nossa argumentação.

\section{O Édipo em Lacan}

Lembremos que um dos grandes méritos do psicanalista francês foi, justamente, emancipar o Édipo - e, na realidade, todo o núcleo duro de sua teoria do sujeito embasada no simbólico - de capturas imaginárias, alçando-o ao seu estatuto puramente formal e lógico. Em outras palavras, na esteira do nascente estruturalismo, Lacan opera durante a década de 1950 uma desvinculação da teoria psicanalítica de apreensões fenomenológicas ou experienciais seja na clínica, seja na própria concepção de processos de subjetivação, em nome de sistemas de funcionamento universais, mas vazios em seu conteúdo. Assim, a partir da recepção particular da linguística saussuriana, a escuta em psicanálise passa a orientar-se não mais por ideias, afetos e lembranças, mas por significantes que, por sua vez, adquirem valor apenas em cadeias significantes, por oposições que têm a diferença pura como seu fundamento. Esse tipo de operação é o que permite que a psicanálise se emancipe de sua dívida inconfessa o biologismo ainda presente Freud, proporcionando toda uma nova matriz de compreensão da subjetividade humana. Mais ainda, tal como na antropologia e na linguística, tal postura permitiria à psicanálise ir além da apresentação intuitiva do fenômeno e explorar os meandros propriamente inconscientes da estrutura do sujeito.

O complexo de Édipo, nesse sentido, que se aproximava em Freud da experiência concreta da família vitoriana, bem como da visão do genital do sexo oposto - significada pela fantasia de castração ou inveja do pênis - estaria em Lacan, a princípio, desvinculado de tais coordenadas imaginárias. Trata-se, antes, de um processo lógico a partir do qual o sujeito vem a se constituir enquanto alienado no desejo do Outro - instância de alteridade radical que não se confunde com o outro da experiência intersubjetiva. A castração desvincula-se aí também da referência à experiência e converte-se na marca negativa do desejo, cuja lida em termos de recalque configuraria a neurose e, em termos de uma 
foraclusão - i.e. uma expulsão mais radical desse hiato que configura o desejo - configuraria a psicose. Não por outro motivo, a castração surge, em primeiro lugar, no campo do Outro, para que só então o sujeito neurótico venha a fantasiar ser, falicamente, aquilo que faltaria ao Outro. O Édipo em Lacan é, assim, um processo lógico de três tempos, que conduz a criança de um estado onde a necessidade e a privação vertem-se, em primeiro lugar, numa frustração e numa constituição imaginária do objeto fálico para só na passagem a um terceiro tempo instaurarem propriamente o desejo enquanto categoria pura, dada pela substituição do desejo materno pelo nome-do-pai, epítome simbólica que serviria como chave para que a criança possa, metonimicamente, buscar preencher essa falta fundamental com os mais variados tipos de objetos.

Mas, retomando o fio da meada de nossa questão, é importante sublinhar que, em Lacan, a função estruturadora da identidade sexual que esse complexo cumpre é, a partir do simbólico, uma sorte de realização tardia que adviria apenas em seu terceiro tempo. Assim, após a separação da criança do desejo materno e da instituição da castração materna, o nome-do-pai se apresentaria por meio de uma metáfora do desejo da mãe, instaurando, assim, a ordem simbólica neuroticamente centrada. E é apenas a partir daí que se daria a chamada assunção do tipo ideal do sexo. Segundo Faria (2010, p.73), "é no terceiro tempo que temos a configuração final do complexo de Édipo. É pelo terceiro tempo que se pode, finalmente, definir o Édipo como um ordenador da sexualidade humana [...]".

O que é digno de nota, no entanto, é que, precisamente no que tange à questão da identidade sexuada, há um inesperado e atropelado retorno do imaginário anatômico lá onde poderia se esperar uma coroação do simbólico enquanto estruturador do desejo negativo. Se durante os dois primeiros tempos do Édipo é bastante claro que o falo não é o pênis, mas o significante do desejo do Outro, ao final do Édipo ele encontraria - um tanto mágica e necessariamente - justamente esse mesmo objeto que a tônica lacaniana insiste em separar do significante. "É nessa medida que o complexo de Édipo pode ser transposto, isto é, a etapa da identificação, na qual se trata de o menino se identificar com o pai como possuidor do pênis, e de a menina reconhecer o homem como aquele que o possui" (Lacan, 1999, p.203). Assim, como se nada fosse, o avançado e estrutural Édipo lacaniano acaba por imaginarizar a entrada na sexuação a partir, justamente, da separação que o funda.

Faria $(2010$, p.83) aponta com muita precisão o paradoxo no qual nossa crítica se aloja:

Ao final do Édipo, o que se tem, portanto, é o final de uma construção, que é da identidade sexual. Entretanto, esse final aponta para um paradoxo em relação ao papel da anatomia na construção da sexualidade: de um lado, a teoria psicanalítica mostra que a anatomia não é o fator decisivo, que a construção da identidade sexual depende, antes de mais nada, de um ordenador simbólico - o falo -; por outro, ao final do percurso em que o falo constitui-se como esse ordenador simbólico, que recobre e re-significa 
o dado anatômico, reencontramos a posição do menino como portador do falo e da menina como aquela que não o tem e deve buscá-lo. Afinal, seria a anatomia o destino que o percurso edipiano só viria ratificar?

De certa forma, sim, ao menos levando-se em consideração o que Freud e Lacan propõem como as saídas "normais" do complexo de Édipo.

Ou seja, toda a potência conceitual e clínica que o Édipo estrutural aportaria para as discussões psicanalíticas referentes à estruturação do sujeito recaem, no campo da sexualidade, numa discussão sobre normalidade e prevalência da anatomia. Reforcemos nosso argumento a partir de outra perspectiva.

$\mathrm{Na}$ célebre passagem do seminário sobre as formações do inconsciente (Lacan, 1999) - no auge da redescrição estruturalista do complexo de Édipo e de sua teoria da constituição subjetiva a partir da entrada na linguagem -, veremos Lacan fazer uma diferenciação da função do referido complexo a partir de "três polos". Um primeiro seria referente às questões do supereu e das neuroses sem Édipo (Lacan, 1999, p.170); um segundo diria respeito às "questões concernentes às perturbações que se produzem no campo da realidade"; e, finalmente, um terceiro, "não menos merecedor de comentários: a relação do complexo de Édipo com a genitalização, como se costuma dizer. Não se trata da mesma coisa" (ibidem, p.170).

E Lacan prossegue:

Por um lado - ponto que muitas explorações e discussões na história fizeram passar para o segundo plano, mas que continua implícito em todas as clínicas -, o complexo de Édipo tem uma função normativa, não simplesmente na estrutura moral do sujeito, nem em suas relações com a realidade, mas quanto à assunção de seu sexo [...] (ibidem, p.170, grifos nossos)

As clínicas, portanto, demonstrariam que a função normativa do Édipo continuaria implícita não apenas no que diz respeito a questões morais e de relação com a realidade, mas igualmente à assunção de seu sexo. Em seguida, Lacan fará uma curiosa pontuação - se nos lembrarmos do contexto estruturalista de sua emergência - sobre a maturação biológica, ligando-a a uma questão orgânica e filogenética (ibidem, p.169), para em seguida emendar dizendo:

A questão da genitalização é dupla, portanto. Há, por um lado, um salto que comporta uma evolução, uma maturação. Por outro, há no Édipo a assunção do próprio sexo pelo sujeito, isto é, para darmos nomes às coisas, aquilo que faça com que o homem assuma um tipo viril e com que a mulher assuma um certo tipo feminino, seja reconbecida como mulher, identifique-se com suas funções de mulher. A virilidade e a feminização são os dois termos que traduzem o que é, essencialmente, a função do Édipo. (ibidem, p.170, grifos nossos)

É bastante emblemático que, nesse momento do percurso lacaniano, as definições que ligam o Édipo à questão da sexuação - que aqui é, não por acaso, chamada de genitalização - sejam descritas não em termos simbólicos, mas imaginários: seja pela constatação de que está em jogo uma maturação filoge- 
nética, passando pela "assunção do próprio sexo" - que, dada a ambiguidade do termo, refere-se aqui indistinta e acriticamente, para Lacan, tanto aos órgãos genitais quanto à estrutura sexuada do sujeito -; seja pela vaga ideia de tipo viril e tipo feminino - que, para darmos nomes às coisas, aproximam-se muito mais de uma descrição tipológica, próxima aos desenvolvimentos de uma psicologia da personalidade -; seja pelo fato de que ela venha a ser reconbecida como mulher e que se identifique com suas funções de mulher. Ademais, virilidade e feminização traduziriam a função do Édipo. Lembremos que todos esses desenvolvimentos se assentam na ideia de uma lei simbólica proibitiva, que ao mesmo tempo condensa a estrutura da linguagem, da lida neurótica com a falta por meio do recalque, e da assunção da diferença sexual. Compreende-se, assim, porque as experiências transexuais são, por alguns analistas lacanianos, frequentemente remetidas à psicose, dado que estariam fora da lei simbólica fundamental. Lei essa que congregaria, no caráter simbólico da proibição do incesto, uma questão de linguagem, de identificação sexual e de lida com a realidade. Lembremos, não obstante, que uma das principais matrizes conceituais de que Lacan se utiliza para pensar o lugar da lei simbólica junto ao Édipo estrutural é a leitura que faz das Estruturas elementares do parentesco de Claude Lévi-Strauss (2012).

Vejamos em que contexto se dá a primeira evocação a Lévi-Strauss feita por Lacan em seu seminário sobre o eu na teoria de Freud e na técnica da psicanálise:

Foi por isso que eu disse que o complexo de Édipo, com a intensidade fantasística que nele descobrimos, a importância e a presença que tem no plano imaginário para o sujeito com o qual lidamos, devia ser concebido como um fenômeno recente, terminal, e não original, com relação àquilo de que Lévi-Strauss nos fala. (Lacan, 2010, p.43)

Ou seja, a intensidade da fantasia que o Édipo aportaria ao sujeito diz respeito sobretudo a um fenômeno (1) imaginário e (2) recente. Mas qual seria, então, o interesse primeiro de Lacan pela obra de Lévi-Strauss?

Lacan sublinhará nesse seminário, muito pertinentemente, que o antropólogo trabalhará em As estruturas elementares do parentesco (Lévi-Strauss, 2012) justamente o fundamento universal das estruturas elementares, e não das estruturas complexas do parentesco. Antes da introdução da linguística saussuriana, Lacan se empenha, já a partir de 1954, a partir da antropologia, em propor um sistema estrutural que pudesse abarcar a totalidade da ordem humana, cuja função simbólica “intervém em todos os momentos e em todos os níveis de sua existência” (Lacan, 2010, p.46). E vai além:

esta ordem simbólica, já que ela se coloca sempre como um todo, como se formasse por si só um universo - e inclusive constituísse o universo como tal, na medida em que é distinto do mundo -, deve, igualmente, ser estruturada como um todo, ou seja, ela forma uma estrutura dialética que se sustenta, que é completa. (ibidem, p.47, grifos nossos) 
Mas a leitura dessa passagem de 1954 talvez nos levasse a crer que haveria em Lévi-Strauss uma defesa da universalidade natural de uma lei simbólica única, sendo as ditas variações culturais meros epifenômenos. Seria esse exatamente o caso?

\section{O domínio do social}

Analisemos mais de perto algumas passagens de As estruturas elementares do parentesco (Lévi-Strauss, 2012). Uma primeira questão refere-se à diferença sensível entre as estruturas elementares do parentesco analisadas pelo antropólogo e as estruturas complexas, onde se encontrariam, entre outras, as sociedades ocidentais contemporâneas. Um dos grandes méritos de Lévi-Strauss nesse empreendimento foi demonstrar que as regras que proíbem e prescrevem relações de parentesco não decorrem de uma naturalidade biológica de eco evolucionista, mas sim da instauração da condição mesma das relações sociais. Daí que, mesmo reconhecendo que a genética prescreva o aumento de malformações decorrentes dos casamentos consanguíneos, afirma no prefácio à segunda edição da obra que a etnologia não necessitaria de tal hipótese e que continuaria a crer, em 1966, que "a proibição do incesto explica-se inteiramente por causas sociológicas" (Lévi-Strauss, 2012, p.22, grifos nossos).

Vemos assim uma defesa, recorrente ao longo do livro, do afastamento de explicações biológicas para o tabu do incesto, dado que esse só se explicaria pela universalidade de regras para formação de grupos - como a exogamia.

A exogamia fornece o único meio de manter o grupo como grupo, de evitar o fracionamento e a divisão indefinidos que seriam o resultado da prática dos casamentos consanguíneos. [...] o vínculo de aliança com uma familia diferente assegura o domínio do social sobre o biológico, do cultural sobre o natural. (ibidem, p.522, grifos nossos)

Em outra passagem, Lévi-Strauss sublinha igualmente o caráter estrutural referente à posição da maternidade. Assim, aquilo que a biologia considera plenamente localizável na filiação humana, do ponto de vista genético e gestacional, e que a psicanálise pôde pensar em termos de função, a antropologia considerará como uma relação não apenas com os filhos - o que, em certa medida, individualizaria a mãe -, mas sim com a comunidade. A maternidade seria, assim, pensada a partir de uma relação da mulher "com todos os outros membros do grupo, para os quais não é mãe, mas irmã, esposa, prima ou simplesmente estranha no que respeita ao parentesco" (ibidem, p.525).

Mas a primeira grande questão que se apresenta a Lévi-Strauss é que uma tal constituição societária dessa natureza possui diferenças sensíveis em relação à nossa configuração ocidental contemporânea, por, ao menos, dois motivos.

Um primeiro é econômico, posto que o sistema de trocas e alianças é, em realidade, uma forma que tem como resultado o estabelecimento do simbólico e das políticas de aliança, mas que, inversamente, precisa de tal funcionamento social para garantir sua sobrevivência. Assim, o casamento nas sociedades primitivas, em relação às sociedades modernas, 
[...] apresenta uma importância completamente diferente, não erótica, mas econômica. A diferença entre a situação econômica do solteiro e a do homem casado em nossa sociedade reduz-se quase exclusivamente ao fato de o primeiro dever mais frequentemente renovar seu guarda-roupa. A situação é inteiramente diversa nos grupos onde a satisfação das necessidades econômicas repousa inteiramente sobre a sociedade conjugal e sobre a divisão do trabalho entre os sexos. (ibidem, p.77)

Uma segunda razão - articulada com a primeira - que apresenta diferenças entre sociedades modernas e as teses de Lévi-Strauss refere-se à questão da escolha e, em última análise, à do desejo. As estruturas elementares do parentesco guiam - consciente e inconscientemente - as possibilidades de contração de matrimônio em um quadro de escassez econômica e necessidade de estruturação da comunidade; e, por isso, acabam sendo, de fato, muito mais detalhadas do que as estruturas complexas - que seriam, segundo Lacan, caracterizadas por serem "muito mais amorfas" (Lacan, 2010, p.47).

Amorfas ou polimorfas? O fato é que o casamento moderno ${ }^{2}$ parece prescindir do excesso de tais categorias normativas, ao mesmo tempo que introduz uma variável que Lévi-Strauss, estratégica e metodologicamente, exclui de sua análise: a história pessoal, os gostos, e, enfim, aquilo que convencionou-se considerar na modernidade como indivíduo.

Lévi-Strauss precisa, em 1966, que a diferença entre as estruturas elementares e complexas se dá quando a escolha do cônjuje ultrapassa os critérios de parentesco, quando se explica "pelo fato de a esposa desejada ser loura, esbelta, ou inteligente" (Lévi-Strauss, 2012, p.28), sendo que, nesse caso, "trata-se sem dúvida de um critério social, cuja apreciação é relativa, não sendo estruturalmente definido pelo sistema" (ibidem, p.28, grifos nossos).

Ao sublinhar o problema existente em analisar as relações de partentesco em grupamentos humanos mais numerosos e fluidos, perder-se-ia a fineza da análise propiciada pelas estruturas elementares, que reduzem drasticamente o lugar da escolha pessoal. E sobre esses grupos de caráter mais polimorfo, o antropólogo se pergunta:

Mas como saber se, sem perceber, faz alguma coisa a mais (ou a menos) do que seria o caso se seus membros escolhessem o cônjuje em função de sua história pessoal, ambições e gostos? É nesses termos, segundo me parece, que se levanta o problema da passagem das estruturas elementares às estruturas complexas, ou, se preferirmos, da extensão da teoria etnológica do parentesco às sociedades contemporâneas. (ibidem, p.29)

Evidentemente nossa evocação dessa diferença não está a serviço de um subjetivismo ingênuo, quase pré-freudiano. A aparentemente mais livre escolha, de alguma maneira, sempre estará sobredeterminada por uma estrutura, por um discurso, por um Outro, por outros ou por um real. Ocorre que, ao importar muito rapidamente o quadro lévi-straussiano para o interior do registro simbólico, Lacan parece perder de vista algumas especificidades centrais, cujos 
efeitos serão sentidos em sua descrição "estrutural" do parentesco; e, consequentemente, da difença sexual, posto que a totalidade que o simbólico assume em determinado momento do ensino de Lacan faz que a assunção de uma dada identidade sexuada seja edipianamente concebida.

Discutindo a leitura lacaniana de Antígona (Sófocles, 441 a.C./1990), Butler (2014), ao retomar uma preciosa ressalva feita por Hyppolite no Seminário $2, \operatorname{logo}$ após a apresentação de Lacan de sua leitura de Lévi-Strauss - na qual o filósofo sublinha que o simbólico, para Lacan, teria uma função de transcendência, posto que não se poderia nem nele estar, nem dele sair (Lacan, 2010, p.58) -, afirmará que:

Se, tal como Lacan argumenta, Antígona representa um tipo de pensamento que se opõe ao simbólico e, portanto, se opõe à vida, talvez isso ocorra justamente porque os próprios termos da viabilidade da vida [livability] encontram-se estabelecidos por um simbólico que é desafiado pelo tipo de reivindicação que ela faz. (Butler, 2014, p.81, grifos nossos)

$O$ simbólico ou $u m$ simbólico? Essa pergunta seria um contrasenso na interpretação clássica de Lacan, na medida em que suporia que o simbólico enquanto tal poderia, de alguma forma, ser comparado a formas culturais específicas, e não a uma lei humana universal e intocável. Shepherdson (apud Cossi, 2017 , p.143), por exemplo, critica a interpretação segundo a qual Irigaray proporia um "simbólico feminino", na medida em que "essa empreitada só faria sentido se se equalizassem simbólico e contexto sócio-histórico, o que não se dá em Lacan e nem na teoria de Irigaray".

Mas voltemos a Lévi-Strauss. Qual é, de fato, o conceito de "lei" e de "universal” em jogo em sua teoria?

\section{Incesto: a dobradiça entre o universal e o cultural}

Em primeiro lugar, é preciso lembrar que Lévi-Strauss discutirá sempre sistemas simbólicos, nos quais não haveria, por um lado, nem uma estrutura absolutamente elementar que prescrevesse com precisão qual o cônjuje será escolhido, nem, por outro, nenhum sistema no qual haveria uma liberdade irrestrita para contração de matrimônio (Lévi-Strauss, 2012, p.15). Assim, As estruturas elementares do parentesco é um conjunto de descrições detalhadas de diferentes modalidades culturais de estabelecimento de proibições e prescrições matrimoniais em que - graças à sua descrição estrutural - fenômenos como o casamento entre irmãos ou entre adultos e crianças de menos de dois anos de idade de maneira alguma romperiam o tabu do incesto, mas o explicaria, na medida em que tais alianças se submetem a outras regras culturais. Contudo, não está em jogo em Lévi-Strauss uma defesa do caráter irredutível do culturalismo, tampouco uma crítica ao universalismo.

Um dos maiores méritos desse trabalho do antropólogo foi, precisamente, instituir uma saída metodológica fundamental à dicotomia entre natureza e cultura, universal e particular, lei e norma, universo e mundo. A definição 
estrutural do incesto funciona para o antropólogo como um objeto de pesquisa que permite articular essas duas dimensões, na medida em que o incesto se insere cultural e diferencialmente em cada sociedade de maneira variada - sendo, no entanto e ao mesmo tempo, o universal e o natural, pois não há sociedade que não prescreva algum tipo de norma. O universal do incesto é, portanto, a estrutura mesma de sua variação; ou, em outras palavras, a única coisa que a lei universal prescreve é que há normas. Nas palavras do próprio autor:

[...] os dois critérios, o da norma e o da universalidade, oferecem o princípio de uma análise ideal que pode permitir - ao menos em certos casos e certos limites - isolar os elementos naturais dos elementos culturais que intervêm na síntese de ordem mais complexa. Estabeleçamos, pois, que tudo quanto é universal no homem depende da ordem da natureza e se caracteriza pela espontaneidade, e que tudo quanto está ligado a uma norma pertence a uma cultura e apresenta os atributos do relativo e do particular. [...] a proibição do incesto apresenta, sem o menor equívoco e indissoluvelmente reunidos, os dois caracteres nos quais reconhecemos os atributos contraditórios de duas ordens exclusivas, isto é, constituem uma regra, mas uma regra que, unica entre todas as regras sociais, possui ao mesmo tempo o caráter de universalidade. (Lévi-Strauss, 2012, grifos nossos)

É precisamente essa articulação elíptica que se perde de vista ao considerarmos, em psicanálise, "o simbólico" muito rapidamente como sinônimo de "o universal", opondo-o frontalmente às culturas nas quais ele se apresenta. Essa posição contraria frontalmente toda a postura e todo o percurso lévi-Straussiano, supondo que é possível conceber a "lei simbólica" como imediata, posto que a única lei universal possível para Lévi-Strauss se extrai precisamente do funcionamento das diferentes normas sociais: "se a raiz da proibição do incesto está na natureza, entretanto, é apenas por seu termo, isto é, como regra social, que podemos apreendê-la" (Lévi-Strauss, 2012, p.67, grifos nossos).

Assim, a frequente crítica de “sociologização do simbólico" é, pura e simplesmente, uma contradição: o simbólico é a própria fronteira entre um dado funcionamento social e o fato de que todo funcionamento social carece de normas de parentesco e de aliança. É a análise de cada cultura, portanto, que revelará a maneira pela qual o simbólico se inscreve e produz possibilidades e proibições. Pensar o universal do incesto, assim, passa longe de elevar a interdição de uma função paterna ao acesso de uma mãe proibida a uma categoria metafísica ou metassocial, mas antes sublinhar que a proibição do incesto "não se exprime sempre em função das regras de parentesco real, mas têm por objeto sempre os indivíduos que se dirigem uns aos outros empregrando certos termos" (ibidem, p.68). E, nesse sentido, "é a relação social, situada além do vínculo biológico implicado pelos termos 'pai', 'mãe', 'filho', 'filha', 'irmão' e ‘irmã', que desempenha o papel determinante" (ibidem, p.67).

A interpretação enviesada feita por Lacan e pelos pós-lacanianos do conceito de "incesto" em Lévi-Strauss, resultando numa "lei simbólica” que uni- 
versaliza e desculturaliza sua aplicação, tem ainda mais um capítulo. Na maneira pela qual a psicanáise usualmente lê essa discussão antropológica parece haver uma implicação evidente entre a proibição do incesto e a sexualidade - o que é bem verdade em Freud, dado que ele parte das fantasias infantis e da referência direta ao mito de Édipo. Contudo, essa aproximação entre proibição e sexualidade não é, de maneira alguma, amparada pelo estruturalismo antropológico de Lévi-Strauss.

O caráter universal da proibição do incesto diz respeito, precisamente, às modalidades de matrimônio e formação de alianças, mas não à maneira pela qual a sexualidade é gerida. O termo incesto aqui acaba servindo a uma ambiguidade conveniente a Lacan, quando, por exemplo, cita Lévi-Strauss, mas tem em mente o incesto enquanto desejo em Freud, ligando-o a das Ding no seminário sobre a ética da psicanálise (Lacan, 2008a , p.84); ou quando enuncia que, para a psicanálise, a lei fundamental do sexo é a interdição do incesto, já que não haveria nenhum "ato sexual” que não tivesse uma relação referencial fundamental ao casal parental, novamente citando o antropólogo (ibidem, p.300).

Lévi-Strauss, no entanto, é bastante claro quanto a essa distinção, na medida em que, frente ao potencial desequilíbrio que a proporção entre homens e mulheres assumiria nas sociedades por ele estudadas, o fato que estabelece a necessidade das normas de parentesco é econômico e social, e não erótico (Lévi-Strauss, 2012, p.77). Assim, frente à questão mais fundamental em jogo,

Suas implicações sexuais são secundárias. A sociedade primitiva, com efeito, ainda mais do que a nossa, dispõe de múltiplos meios para resolver esse aspecto do problema. A homossexualidade em alguns grupos, a poliandria e o empréstimo de mulheres em outros grupos, e finalmente quase em toda parte a extrema liberdade das relações pré-maritais, permitiram aos adolescentes conseguir facilmente uma esposa, se a função de esposa se limitasse às satisfações sexuais. (ibidem, p.76, grifo nosso)

Assim, a centralidade do Édipo enquanto instância simbólica e organizadora tanto da subjetividade quanto da sexualidade e da sexuação distancia-se mais ainda das problemáticas lévi-Straussianas em jogo em As estruturas elementares. É importante pontuar que, ao apresentar esses problemas, nem foi preciso recorrer à longa esteira da crítica feminista ao androcentrismo da análise de Lévi-Strauss e/ou de sua importação acrítica por Lacan - em Rubin (1993), Collier e Yanagisako (1987) e Schneider (1980), por exemplo. Ainda que se trate de uma discussão central, ao considerar a antropologia estrutural nas discussões ligadas ao gênero, uma retomada dessas análises nos levaria demasiado longe do nosso escopo. Levantemos agora uma última e talvez mais importante discussão presente nas estruturas elementares, discussão essa que parece ser sensivelmente ignorada por Lacan no momento da redescrição estrutural do Édipo, nos anos de 1950. 


\section{O caráter secundário da proibição e a questão das alianças}

O papel da universalidade da cultura do incesto é, em Lévi-Strauss, precisamente aquele que aponta - ao contrário de uma leitura classicamente edipiana - a separação da determinação direta entre filiação, sexualidade e laço social a partir de um quarto termo que sobredetermina todos os outros: "se a relação entre pais e filhos é rigorosamente determinada pela natureza dos primeiros, a relação entre macho e fềmea só é determinada pelo acaso e pela probabilidade" (Lévi-Strauss, 2012, p.69). No entanto, após discutir a anterioridade da natureza em relação à cultura, o autor vai localizar precisamente o momento no qual a cultura surge e intervém:

Mas a cultura, impotente diante da filiação, toma consciência de seus direitos, ao mesmo tempo que de si mesma, diante do fenômeno, inteiramente diferente, da aliança, o único sobre o qual a natureza já não disse tudo. Somente aí, mas por fim também aí, a cultura pode e deve, sob a pena de não existir, afirmar "primeiro eu" e dizer à natureza: "Não irás mais longe". (ibidem, p.69, grifo nosso)

Sublinhemos o ponto onde a força do argumento do antropólogo se mostra com maior brilho: as diversas regras que regulam o incesto nas diferentes sociedades estudadas por Lévi-Strauss têm como função não fundar o desejo enquanto categoria negativa, nem mesmo regular o gozo instaurando uma "lei simbólica" de acesso ao corpo do outro, mas, antes, de formar alianças. O que emanciparia, assim, o humano do domínio da natureza é essa capacidade de mutabilidade no estabelecimento de laços, que tem como contrapartida a instauração de normas de regência da circulação de bens, palavras e pessoas.

O problema [da articulação entre natureza e cultura] esclarece-se quando admitimos a indiferença da natureza - corroborada por todo o estudo da vida animal - às modalidades das relações entre os sexos. Porque é precisamente a aliança que fornece a dobradiça, ou mais exatamente o corte, onde a dobradiça pode fixar-se. A natureza impõe a aliança sem determiná-la, e a cultura só a recebe para definir-lhe imediatamente as modalidades. Assim se resolve a aparente contradição entre o caráter de regra da proibição e sua universalidade. A universalidade exprime somente o fato de a cultura, ter sempre e em toda a parte, preenchido essa forma vazia, assim como uma fonte jorrante preenche primeiramente as depressões que cercam a sua origem. (Lévi-Strauss, 2012, p.69, trad. modificada)

O universal é, assim, indiferente às modalidades de relações entre os sexos e - avançaríamos -, igualmente, às suas pretensas definições, nomeações ou números. Qualquer uso dessa discussão antropológica para defender uma lei simbólica calcada na "diferença sexual" que um Édipo heterocentrado aportaria ignora que o ponto central da tese de Lévi-Strauss é, precisamente, o caráter fluido e maleável com o qual as diferentes culturas inventam regras para lidar com suas alianças, com seus dispositivos de formação de grupos e suas relações. 
Desse modo, a mais grave transgressão não é ignorar o tabu sexual referente a parentes cujo matrimônimo é, em determinada cultura, proscrito, mas antes abster-se de contribuir para o fortalecimento do grupo e de suas alianças. Lévi-Strauss narra que uma das impressões mais profundas que guarda de suas primeiras experiências etnográficas no Brasil refere-se à visão de um jovem "acocorado horas inteiras no canto de uma cabana, sombrio, malcuidado, terrivelmente magro e, ao que parecia, no estado de mais completa abjeção" (Lévi-Strauss, 2012, p.77, grifo nosso). Esse jovem raramente saía, estava sempre solitário e, por vezes, dependida de parentes para alimentar-se. "Quando, intrigado com este singular destino, perguntamos finalmente quem era este personagem, a quem atribuíamos alguma grave doença, responderam-nos, rindo de nossas suposições: 'é um solteiro'" (ibidem, p.77).

Pierre Clastres (1978), em seu clássico "O arco e cesto", descreve uma situação semelhante, aproximando ainda mais diretamente as questões de sexuação que nos interessam. Ao analisar os guayaki, Clastres percebe uma oposição clara entre homens e mulheres referente às suas atribuições sociais no interior da tribo: os homens carregavam arcos e as mulheres carregavam cestos. Há, inclusive, um tabu que prescreve maldições para quem tocar o objeto não prescrito para seu sexo. Tal distinção, evidentemente, refletia as diferenças nas atividades sociais e de sobrevivência. Ocorre que havia na comunidade dois homens que não portavam arcos, mas cestos. Um era viúvo e com dificuldades em se integrar junto à sua família e caçar; o outro, "um pederasta", que utilizava seu cesto em atividades junto às mulheres da tribo.

Na mesma esteira do observado por Lévi-Strauss, Clastres nota que quem é sujeito à abjeção é, justamente, o nativo que se alija do laço social, e não, como poderia se esperar, o "invertido inconsciente" (sic), dado que ele cumpre todas as funções do que poderíamos inferir como gênero feminino - inclusive do ponto de vista sexual, com outros homens; e, por isso, a sociedade trata o fato de aquele homem carregar um cesto como algo aparentemente indiferente. $\mathrm{O}$ critério de humanidade aqui é, portanto, o fato de pertencer claramente a um grupo de forma coesa aos discursos e regras de uma determinada cultura.

Lévi-Strauss (2012, p.79) insistirá na importância da subordinação da família ao grupo, renegando a "anterioridade institucional da família sobre o grupo". E irá além, afirmando que, "em seu aspecto puramente formal, a proibição do incesto, portanto, é apenas a afirmação, pelo grupo, que em matéria de relação entre os sexos não se pode fazer o que se quer. O aspecto positivo da interdição consiste em dar início a um começo de organização" (ibidem, p.81, grifos no original).

O incesto é, assim, maneira pela qual um determinado grupo gera e gesta suas fronteiras, que são, ao mesmo tempo, sua condição de sobrevivência. Ao rechaçar a hipótese genética da proibição do incesto, Lévi-Strauss insiste que, sem essa, as famílias tenderiam a se ensimesmar e impossibilitar a vida social pro- 
priamente dita. É, portanto, visando estabelecer alianças - que são num mesmo movimento individuais e sociais - que o casamento se sustenta, sendo a exclusão de determinadas modalidades de laço um meio para tal. A proibição, assim, tão central para Lacan, parece ter em Lévi-Strauss um estatuto secundário à ordem simbólica em si.

A demonstração do caráter prescritivo que a proibição mascararia é dada por um exemplo que o antropólogo retira de Margaret Mead, quando esta indaga informantes arapeshe sobre o que aconteceria ao se romper a proibição, por exemplo, casando-se com a irmã. $\mathrm{O}$ arapeshe tem extrema dificuldade em entender a pergunta de Mead, na medida em que se pergunta "por que alguém faria isso?". Após muita insistência, ele então responde ao que diria ao supostro transgressor: "O que há contigo? Não queres ter cunhado? [...] [Não compreendes que] se te casares com a própria irmã, não terá nenhum? E com quem irás caçar? Com quem fará as plantações? Quem irás visitar?" (Mead apud Lévi-Strauss, 2012, p.528 ).

Diferentemente do que esperaríamos ouvir caso nossa alma edipiana fosse, de fato, universal e estrutural, a transgressão do incesto não representa, junto às estruturas elementares do parentesco, uma potencial dissolução da lei com graves consequências morais ou jurídicas, nem um tipo de denegação ou foraclusão. Ela está mais ligada a um nonsense, a um real fora da razão simbólica humana, na medida em que impede o laço social baseado na unidade do grupo - este, sim, essencial. Não por outro motivo Lévi-Strauss (2012, p.529) afirma que a proibição do incesto e a exogamia têm uma função "essencialmente positiva" e que "sua razão de ser consiste em estabelecer, entre os homens, um vínculo sem o qual não poderiam elevar-se acima da organização biológica para atingir a organização social".

Estas [proibições do casamento] são só proibições em caráter secundário e derivado. Antes de serem uma proibição que afeta uma certa categoria de pessoas, são uma prescrição que visa a outra categoria. Como a teoria indígena a esse respeito é mais clarividente do que tantos comentários contemporâneos! Nada existe na irmã, na mãe, nem na filha que as desqualifique enquanto tais. $\mathrm{O}$ incesto é socialmente absurdo antes de ser moralmente culpável. A exclamação incrédula arrancada ao informante: Mas então não queres ter cunbado? fornece a regra de ouro do estado da sociedade. (Lévi-Strauss, 2012, p.529, negritos nossos)

O cunhado aparece aqui como o objeto simbólico central que se esconde atrás da proibição. Talvez não por outro motivo seja a ambiguidade presente na noção de "cunhado" e "irmão" em algumas tribos brasileiras que vá ser evocada pelo antropólogo como prova de que a troca de mulheres não seria a única forma de estabelecimento de alianças. Diferentemente do irmão, cujo paradigma é aquele da solidariedade mecânica, o cunhado - com quem, sublinha Lévi-Strauss, o sujeito teve, na infância, trocas homoafetivas - possui uma eficácia funcional, ligada à solidariedade orgânica. Esta, diferentementemente da 
primeira, que não acrescentaria nada, "realiza uma integração do grupo em um outro plano" (Lévi-Strauss, 2012, p.528, grifo nosso).

Assim, a partir dessa leitura de Lévi-Strauss, temos que a discussão da lei, universal, é apenas um lado do simbólico. No limite, seria aquele que no fundo menos corresponderia ao simbólico em si na medida em que a lei universal quase pertenceria ao domínio do natural, já que é no campo local da instauração cultural da aliança que o propriamente humano sobrepujaria o domínio de uma universalidade inespecífica (Lévi-Strauss, 2012, p.69). Para nossos propósitos, portanto, do ponto de vista simbólico, importaria pouco o fato universal de que para todo ser falante há um sexo, e muito mais a maneira pela qual cada sistema simbólico instaura suas balizas de grupo e de relações prescritas e proibidas. Em outras palavras, para nossos propósitos, seria preciso pensar um simbólico não pautado pela lei de uma interdição específica, mas antes pela análise das normas simbólicas locais segundo as quais o princípio universal de uma sexuação se coloca como necessário. Seguindo os passos do antropólogo, portanto, o caráter proibitivo de qualquer instância normativa no que tange as identidades sexuais teria como fim último a possibilidade do estabelecimento de tais alianças e não o contrário, como uma determinada leitura de Lacan levaria a crer. Assim, uma sociedade orientada, por exemplo, por um horizonte heteronormativo de relações matrimoniais, tende a produzir proibições de transgressão de gênero, como as transidentidades, na medida em que estas colocariam em perigo as regras de aliança ali em jogo, ao desestabilizarem a correspondência entre sexo e gênero.

Bem entendido, refundar o simbólico deslocando o paradigma da lei para aquele da norma não é uma tarefa simples ou mesmo possível no âmbito de um artigo. Não obstante, propomos aqui, seguindo os passos de Lévi-Strauss apagados por Lacan, a necessidade de considerar a sexuação enquanto um processo de subjetivação simbólico que se dá em função do estabelecimento de uma determinada posição dentro de um dado grupo.

Ser sexuado é, assim, não propriamente identificar-se ao significante "homem" enquanto complementariamente oposto a "mulher", ou vice-versa, nem assumir um "tipo viril" ou "tipo feminino" no último tempo do Édipo (Lacan, 1999, p.170); tampouco identificar-se como tendo ou sendo o falo (ibidem); mas, antes, identificar-se como tendo uma dada posição frente a um grupo de outros, cuja norma prescreve regras de aliança, de relação e de proibição, mas sempre com um horizonte último de coesão social. Se o "Mas então não queres ter cunhado?", de acordo com Lévi-Strauss (2012, p.529), fornece a regra de ouro da sociedade, elevando as normas de aliança entre pares à centralidade do corpo social, é preciso pensar que a assunção do ser sexuado advém, igualmente, das balizas simbólicas segundo as quais a pertença a um determinado gênero se dá.

Isso não significa uma ignorância completa, por exemplo, dos determinantes biológicos em jogo nas determinações de gênero, mas que eles estão sempre submetidos ao que dita determinada norma a respeito de sua função simbólica 
no interior de um dado grupo. Se, numa dada sociedade, a sexuação se organiza como um processo atrelado a um quadro biopolítico e jurídico no qual o sexo anatômico implica um gênero "correspondente", a norma simbólica a partir da qual a identificação binária ao grupo "homens" ou "mulheres" se constrói vai orbitar precisamente ao redor dessa diferença. Assim, tornar-se homem ou muther, nesse contexto, se reportaria menos à "realidade corporal" do que daquilo que esse diferença implica termos de uma identificação simbólica de posição social dentro de um ou de outro grupo.

Já estamos longe, assim, de uma leitura tipológica que considere a identificação simbólica como a assunção, pelo sujeito, de um “tipo feminino” ou de um "tipo viril”, conforme lemos em Lacan, no Seminário 5. O simbólico, precisamente por se afastar do caráter fixo que o significado imporia ao significante, é o domínio onde a sexuação se emanciparia da ideia de tipos ideais dados, a partir dos quais os sujeitos passivamente se identificariam. Simbolicamente, portanto, ser hermafrodita, homem, butch, gay, mulher, gender fluid etc. é, assim, não uma identidade fechada nem um script bem delimitado de atos, práticas e discursos. Antes, aquilo que pressupõe a existência de um universal é a multiplicidade de maneiras pelas quais a sexuação se constitui enquanto forma pura e, portanto, fluida em seus conteúdos e pela qual cada sujeito sexuado escapa da abjeção social, instaurando sua posição frente à comunidade sem que a vida e o laço social estejam ameaçados pela ininteligbilidade ou pela expulsão.

\section{Notas}

1 Atualmente, grande parte das discussões lacanianas em relação às problemáticas de gênero referem-se à introdução do registro do real, da problemática do gozo e, principalmente, às chamadas "Fórmulas da Sexuação". Discutimos tais questões alhures (Ambra, 2015 ; 2017), mas gostaríamos de explorar, neste artigo, mais a fundo alguns detalhes das matrizes que dão origem ao registro simbólico em Lacan, procurando defender que já aí existem elementos que permitem uma subversão de sua concepção clássica.

2 Que, aliás, é hoje já sensivelmente distinto do que fora nos anos 1950; e, por sua vez, de significação muito distinta na França e no Brasil, por exemplo.

\section{Referências}

AMBRA, P. O que é um homem? Psicanálise e história da masculinidade no Ocidente. São Paulo: Annablume, 2015.

AMBRA, P. E. S. Das fórmulas ao nome: bases para uma teoria da sexuação em Lacan. 2017. Tese (Doutorado) - Instituto de Psicologia, Universidade de São Paulo, Sorbonne Paris Cité - Université Paris Diderot. São Paulo, 2017.

BACARJI, A. D. A ideologia de gênero. Disponível em: <https://formacao.cancaonova. com/afetividade-e-sexualidade/a-ideologia-de-genero/>. Acesso em: 20 ago. 2017. 
BUTLER, J. O clamor de Antígona. Trad. A. Cechinel. Florianópolis: Editora da UFSC, $2002 / 2014$.

CLASTRES, P. O arco e o cesto. In: A sociedade contra o Estado: pesquisas de antropologia política. Trad. T. Santiago. Rio de Janeiro: Francisco Alves Editora, 1978. p.71-9.

COLLIER, J. F.; YANAGISAKO, S. J. Gender and kinship: essays toward a unified analysis. Palo Alto: Stanford University Press, 1987.

COSSI, R. K. A diferença dos sexos: Lacan e o feminismo. 2017. Tese (Doutorado) Instituto de Psicologia, Universidade de São Paulo. São Paulo, 2017.

FARIA, M. R. Constituição do sujeito e estrutura familiar: o complexo de Édipo de Freud a Lacan. 2.ed. Taubaté: Cabral Editora e Livraria Universitária, 2010.

HENIG, R. M. Rethinking gender. National Geographic, v. esp., 2017.

LACAN, J. O seminário, livro 5: as formações do inconsciente. Trad. V. Ribeiro. Rio de Janeiro: Jorge Zahar Editor, 1999.

. O seminário, livro 7: a ética da psicanálise. Trad, A. Quinet. Rio de Janeiro: Jorge Zahar Editor, 2008a.

A lógica do fantasma - Seminário de 1966-1967. Trad. Lyra et al. Recife: Centro de Estudos Freudianos de Recife, 2008 b.

- O seminário, livro 2: o eu na teoria de Freud e na técnica da psicanálise. Trad.

M. C. Penot. 2.ed. Rio de Janeiro: Jorge Zahar Editor, 2010.

LÉVI-STRAUSS, C. As estruturas elementares do parentesco. Trad. M. Ferreira. 7.ed. Petrópolis: Vozes, 2012.

PORCHAT, P. Psicanálise e transexualismo - Desconstruindo gêneros e patologias com Judith Butler. Curitiba: Juruá, 2014.

RUBIN, G. O tráfico de mulheres: notas sobre a "economia política" do sexo. Trad. C. R. Dabat. Recife: S.O.S. Corpo, 1993.

SAFATLE, V. Une certaine latitude: normativité et contingence dans la biopolitique de Georges Canguilhem. Filozofski vestnik, 2016, p.57-79.

SCHNAKE, C. Ideologia de gênero, conbeça seus perigos e alcances. Disponível em: <https://destrave.cancaonova.com/ideologia-de-genero-seus-perigos-e-alcances/>. Acesso em: 20 ago. 2017.

SCHNEIDER, D. A critique of the study of kinship. Chicago: University of Chicago Press, 1980.

SOARES, R. Porque os pais devem dizer NÃO à ideologia de gênero, Disponível em: <http://escolasempartido.org/artigos-top/558-porque-os-pais-devem-dizer-nao-a-ideologia-de-genero>. Acesso em: 20 ago. 2017.

SOFOS. Ideologia de género. Disponível em: <http://sofos.wikidot.com/ideologia-de-genero>. Acesso em: 20 ago. 2017. 
RESUMO - O presente artigo visa apresentar uma análise da relação entre lei e norma no contexto da apropriação lacaniana da antropologia estrutural, em especial no que se refere às suas consequências conceituais junto a processos de identificação sexual. São discutidos os limites da formalização do complexo de Édipo e a aspiração universalizante do simbólico em Lacan. Empreende-se, então, uma releitura de As estruturas elementares do parentesco buscando demonstrar o lugar central conferido por Lévi-Strauss à cultura e às variações de normas locais no núcleo duro da chamada lei simbólica. $\mathrm{O}$ artigo conclui, a partir de tais resgates, que a constituição de grupos e as políticas de alianças podem pautar uma outra concepção do caráter simbólico dos processos identificatórios relativos ao gênero.

PALAVRAS-CHAVE: Psicanálise, Gênero, Simbólico, Diferença sexual, Lévi-Strauss, Estruturalismo, Complexo de Édipo, Sexuação.

ABSTRACT - This paper aims to analyze the relation between law and norm in the context of Lacan's appropriation of structural anthropology, particularly its theoretical consequences on sexual identification processes. The limits of the formalization of Oedipus complex are discussed, as well as Lacan's universal aspiration of the symbolic. We undertake an alternative reading of The elementary structures of kinship to show the central role given by Lévi-Strauss to culture and local norms variations. Considering this, the paper concludes that the formation of groups and a politics of alliances may guide a new conception of gender identification processes.

KErWORDS: Psychoanalysis, Gender, Symbolic, Sexual difference, Lévi-Strauss, Structuralism, Oedipus complex, Sexuation.

Pedro Ambra é doutorando da Universidade de São Paulo e da Université Paris Diderot - Sorbonne Paris Cité. @-pedro.ambra@gmail.com

Recebido em 15.9.2017 e aceito em 10.10.2017.

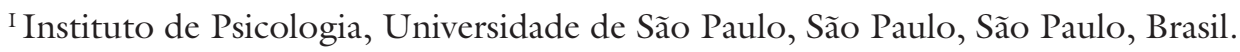

